\title{
EL GESTUS Y LAS PRÁCTICAS FEMINISTAS PERFORMATIVAS
}

\author{
María del Mar Rodríguez Caldas \\ Universidad de Zaragoza. Dpto Expresión Musical, Plástica y Corporal
}

\section{Resumen}

En este artículo examinaremos prácticas artísticas feministas que, en su confrontación con lo real, han indagando en formas de contar desde el cuerpo, retomando la herencia del gestus del teatro brechtiano. Son prácticas que no sólo procuran conocimientos, sino que los producen. Se trata de trabajos que han politizado el cuerpo y los espacios privado y público desde el terreno de lo performativo; pertenezcan por definición al ámbito de la performance o del arte de acción, o se hayan materializado en otros medios, como el fotográfico o el fílmico. Indicaremos una genealogía de obras feministas realizadas en los años 70 y desde los 90 cuya búsqueda común es revelar un gestus social a partir de los cuerpos. Ambos periodos son ricos en prácticas artísticas comprometidas en lo social y en lo político; tras el solipsismo de cierta cultura posmoderna, el activismo del 68 resurgirá en los 90 buscando el reencuentro con la intersubjetividad y con la realidad social (Sánchez 2007).

\section{Palabras-clave: GESTUS BRECHTIANO; CUERPO; PRÁCTICAS FEMINIS- TAS; PERFORMATIVIDAD; ESPACIOS PRIVADO/PÚBLICO}

\section{GESTUS AND PERFORMATIVE FEMINIST PRACTICES}

\section{Abstract}

This paper examines feminist artistic practices that confront the real investigating ways of relating with the body. These practices receive the legacy of the Brecht's theater gestus. They are practices that produce knowledge. These performative artworks have politicized the body and the private and public spaces; they can be performances or action art, or they can use another medium, like photography or film. We note a genealogy of feminist artworks made in the 70's and from the 90's whose common search is the revelation of a social gestus from the bodies. Both periods are productive in artistic practices socially and politically committed. After solipsism reinforced by postmodern culture, 1968 activism reappears in the 90's and the search for a reunion with intersubjectivity and social reality (Sánchez 2007).

Keywords: BRECHTIAN GESTUS; BODY; FEMINIST PRACTICES; PERFORMATIVITY; PRIVATE/PUBLIC SPACES

\footnotetext{
Rodríguez Caldas, María del Mar. "El gestus y las prácticas feministas performativas". AusArt 6 (1): 83-94. D0I: 10.1387/ausart.19404
}

\section{AUSART}




\section{EL GESTUS Y SU HERENCIA MÁS ALLÁ DEL TEATRO}

El teatro épico de Brecht, en su alejamiento de las convenciones teatrales occidentales, se aproxima a lo visual y lo performativo: no se fundamenta en el texto literario sino que es un teatro gestual (su material es el gesto); no busca desarrollar acciones sino exponer situaciones (se aleja de la representación y gira hacia la presentación); no reproduce las situaciones reales, sino que las descubre (rechaza la mímesis, no se trata de replicar la realidad sino de revelarla construyendo algo fabricado).

Aquí nos restringiremos a enlazar uno de los recursos del teatro brechtiano -el gestus- con las técnicas corporales de las prácticas feministas, pero dicho nexo debe ser comprendido en el marco de unas búsquedas de naturaleza indisolublemente estética y política con numerosos puntos en común. Tanto la propuesta brechtiana como la feminista no satisfacen su crítica a los códigos ideológicos de las representaciones a través del contenido; la renovación de los temas no es suficiente sino que son cuestiones de primer orden la renovación de las formas -del lenguaje en sus dimensiones estéticas y técnicas- y la transformación del medio. El teatro de Brecht buscaba transformar el "aparato burgués de producción" (Benjamin 1934); la reflexión feminista caracterizará al aparato, o medio, a transformar como una "tecnología social de género" (de Lauretis 1989).

Otra vinculación fundamental, es que ambas formulaciones reflexionan sobre el espectador y los mecanismos de identificación con la obra. El distanciamento brechtiano forma parte de un programa de ruptura radical con el ilusionismo y con las convenciones del teatro naturalista, pero en última instancia busca producir un nuevo público. Concebidoen oposición a la catarsis de la dramaturgia aristotélica, el efecto del distanciamiento promueve un público reflexivo, impidiendo su proyección en la obra, colocándolo en posición de juzgar aquello que le es presentado y haciéndolo desde una distancia crítica.

Subvertir las representaciones dominantes o desafiar su hegemonía han sido temas centrales en el feminismo. La posición del espectador también ha sido clave en la crítica y la práctica feminista, específicamente en el campo del cine. Del análisis del cine hollywoodiense como una tecnología al servicio de la mirada masculina, Mulvey propondrá, en un influyente ensayo (Mulvey 1975) aniquilar el placer visual y contravenir el ilusionismo y las convenciones narrativas, retomando una herencia que incluye al teatro brechtiano: "Mulvey, 
también, al proponer la destrucción de la narrativa y del placer visual como máximo objetivo del cine de mujeres, saluda una tradición establecida, aunque de izquierda: la histórica tradición de vanguardia que se remonta a Eisenstein y a Vertov (si no a Méliès), y a través de Brecht llega a su máxima expresión en Godard; $y$ del otro lado del Atlántico, a la tradición estadounidense del cine de vanguardia" (De Lauretis [1985] 1992, 258).

En esta búsqueda común por sacar a la luz los aparatos de producción tecno-ideológica y los codigos de representación, el teatro brecthiano y las prácticas feministashan revisado los procedimientos narrativos y la materialización del tiempo y del espacio; aspectos que se entrelazan con la gestualidad corporal.

Las situaciones presentadas en el teatro épico se generan mediante la interrupción de las acciones. Se trata de un principio que ya estaba presente en el procedimiento del montaje -utilizado en el cine, la radio o el fotomontaje- y que Brecht reconvierte a través de lo gestual, partiendo de pequeños elementos de los modos de comportamiento (Benjamin [1934] 2001, 307).

La cualidad de "imagen" del teatro brechtiano es sugerida por Benjamin al indicar que las situaciones son reveladas al quedar enmarcarlas por el gesto, el cual "tiene un comienzo y un final definibles a diferencia de las acciones y empresas de las gentes. Esta índole estrictamente conclusa, a la manera de un marco, de cada elemento de una actitud (que sin embargo se encuentra en un flujo vital), es incluso uno de los fenómenos dialécticos fundamentales del gesto" ([1931] 1999, 19).

De esta propiedad de enmarcado, Benjamin infiere que la estrategia de la interrupción potencia el gesto: "cuanto con más frecuencia interrumpamos al que actúa, tanto mejor recibiremos su gesto" (ibídem).

El carácter recortado y episódico que resulta del espaciamento de las acciones, de su descomposición en gestos, de la sucesión de cuadros, nos permite observar un vínculo con aquellas formas de contar que se sitúan en la frontera entre la imagen fija y la imagen en movimiento, que combinan la imagen estática y la diégesis. Barthes, gran admirador del teatro brechtiano, se había declarado fascinado por el fotograma fílmico y había celebrado el nuevo significante que traían consigo artes populares como el cómic y la fotonovela (Barthes [1970] 1986, 65-6). 
En el arte contemporáneo encontramos un equivalente de esto último en la secuencia fotográfica, recurso frecuentemente empleado para "contar" una performance mediante su registro fotográfico, pero también desarrollado como un formato con entidad propia en las prácticas de carácter performativo. En cuanto al fotograma, Barthes insta a la elaboración de una teoría sobre dicho artificio, toda vez que considera que lo fílmico del futuro "no está tanto en el movimiento como en un tercer sentido" (al cual denomina "sentido obtuso") y que el fotograma constituye una liberación de la constricción del tiempo fílmico, el cual considera un obstáculo para el advenimiento del estado adulto del cine (Barthes [1970] 1986, 66-7).

Una década después, en sus estudios sobre el cine, Deleuze se ocupa del tiempo fílmico y considera que la renovación del cine pasa, precisamente, por la liberación de las coordenadas espacio-temporales propias del cine de acción, el cual había alcanzado sucrisis (Deleuze 1983; 19856).

Deleuze contrapone la "imagen-acción" del cine clásico hollywoodiense, a la "imagen-tiempo" del cine moderno europeo surgido de la posguerra. Caracteriza al primero como un cine que genera situaciones sensoriomotrices en las que el espectador participa por medio de la identificación con los personajes; a diferencia del segundo que generaría situaciones puramente ópticas (como la pintura) y sonoras (como cuadros vivientes), exigiendo del receptor una actitud más reflexiva.

Dentro de este último cine, indagó en una forma de contar que denominó "cine de los cuerpos, en la cual los personajes quedan reducidos a sus propias posturas y actitudes corporales, señalando a la nouvelle vague y post-nouvelle vague como los movimientos que lo llevarían más lejos (Deleuze [1985] 1996, 251-61).

En el "cine de los cuerpos" predomina el cuerpo fatigado, gastado o neurótico, el cual se expresa a través de comportamientos catatónicos, posturas involutivas, infantiles, o bien a través de actitudes histéricas, violentas, explosivas. Deleuze caracteriza este cine retomando la noción del gestus brechtiano; así, considera que el mayor interés se logra cuando de las actitudes o posturas se consigue hacer surgir "el gestus, es decir, un espectáculo, una teatralización o una dramatización" (Deleuze [1985] 1996, 255). Y el autor encuentra una especificidad en las producciones de las mujeres cineastas: en sus personajes femeninos el cuerpo conquista una suerte de nomadismo, atravesando edades, situaciones y lugares; las cineastas desarrollan un "gestus femenino que 
capta la historia de los hombres y la crisis del mundo" (Deleuze [1985] 1996, 260). Destacando a autoras como Michèle Rosier, Agnès Varda o Chantal Akerman, de esta última considera que introduce la innovación de "es mostrar las actitudes corporales como el signo de estados de cuerpo propios del personaje femenino" (citada en Deleuze [1985] 1996, 260).

Además de vincular gestus brecthiano y "cine de los cuerpos", Deleuze también encuentra un nexo con la performance artística de carácter ceremonial. En concreto, alude a la tríada masculina del accionismo vienés (Brus, Müehl y Nitsch), los cuales exploraban el autoanálisis sacrificial y la formación del "yo". Sin embargo, él mismo recuerda que, si bien existen otros tipos de gestus, según lo exigía Brecht el gestus ha de ser necesariamente social (Deleuze [1985] 1996, 254-5). Así, mientras una mera ceremonia sería un gestus vacío, el gestus social tiene un sentido histórico, en él ha de poder "leerse toda una situación social" (Barthes [1973] 1986, 97). El gestus social es el esquema histórico particular que hay en el fondo de una obra, es "la expresión exterior, material, de los conflictos de sociedad de los que es testimonio" (Barthes [1955] 2002, 71).

La generalidad de las performances feministas -incluso aquellas de marcada dimensión ritual (Gina Pane, Ana Mendieta o Marina Abramovic)- no son meras ceremonias (gestus vacío) ni un culto a la violencia gratuita, sino que de ellas emanan gestus plenos de significado social (ciertamente, nos demuestran que "lo personal es político"). Por tanto, no apreciamos tanto una conexión entre el gestus brechtiano, el "cine de los cuerpos" y la performance en general, como entre aquellos y, específicamente, las prácticas feministas de carácter performativo.

\section{GESTUS FEMINISTAS Y POLITIZACIÓN DEL ESPACIO PRIVADO}

El espacio privado ha sido politizado en numerosas obras que revelan un gestus social a partir del cuerpo femenino.

El confinamiento en ese espacio, sus límites asfixiantes, lo insoportable de las rutinas domésticas, la falta de reconocimiento social y de remuneración económica del trabajo en el hogar, la doble jornada laboral, los conflictos de la 
maternidad o las dificultades que suponen los trabajos de cuidados, son situaciones sociales que se pueden leer en una genealogía que, entre otras, enlazaría los dibujos y pinturas de las Femme maison (1946-1947) de Louise Bourgeois, la performance de Chris Rush Scrubbing o la instalación Linen closet de Sandy Orgel -ambas dentro del Womanhouse Project (1972)- la instalación Postpartum document( 1973-79) de Mary Kelly, el film experimental Riddles of the sphinx (1977) de Laura Mulvey y Peter Wollen, el proyecto multidisciplinar Homeworkers (1977) -que incluye fotografías, entrevistas, recortes de prensa y lienzos- de Margaret Harrison, la exposición Who's holding the baby? (1978) -compuesta de caricaturas, collages, fotomontajes y gráficos- de Hackney Flashers Collective, los fotomontajes de la serie Work in progress (1979-80) de Carole Condé y Karl Beveridge, la obra foto-performance Inhabit (2009) de Janine Antoni o la escultura Alicia de Córdoba (2009) de Cristina Lucas.

Utilizando la escenificación fotográfica, el fotomontaje, o el video-performance -con las consiguientes estrategias de teatralidad y de interrupción- han sido aplicados gestos que ironizan sobre la atribución de las tareas de limpieza del hogar en función del sexo. Los fotomontajes Erwartung (1976) de VALIE EXPORT o Untitled (It's a smallworldbutnotifyouhave to cleanit) (1990) de Barbara Kruger; el film en súper 8 Antes de la televisión (1983) de Ximena Cuevas; o la serie fotográfica Libido Uprising (1989) de Jo Spence, son ejemplares.

Circunscribiéndonos a la performance, son pioneras Waiting de Faith Wilding y Cock and cunt play de Judy Chicago, realizadas en 1972 en Womanhouse. En ambas piezas opera una teatralización directa de los cuerpos. En la primera, sentada con el cuerpo recogido, apoyando las manos sobre las rodillas, Wilding recita las expectativas sociales de una mujer desde el nacimiento hasta la muerte. El monólogo expone a lo largo de quince minutos una vida sometida a la infinita espera, un comportamiento domesticado en la pasividad, una existencia condenada a vivir a expensas de las decisiones e iniciativas de los demás. El carácter repetitivo y cíclico del texto se acompaña del balanceo rítmico del cuerpo arqueándose hacia delante, plegándose sobre sí mismo, meciéndose en una postura asilar. El tono monótono y el gesto insistente revelan el cansancio de los roles socialmente impuestos a las mujeres, expresan el hastío histórico. Como proponía Brecht, este gestus social determina la actitud corporal, el tono de voz y la expresión del rostro ([1947] 2004).

En Cock and Cunt Play se plantea la situación de conflicto entre los géneros: los personajes He (interpretado por Faith Wilding) y She (por Janice Lester) van ataviados con órganos sexuales de grandes dimensiones, confiriéndole a la performance un tono cómico y un gesto exagerado, profundamente anti- 
naturalista, que también queda patente en sus movimientos marionetescos y la declamación artificiosa: el espaciamiento silábico en la pronunciación va acompasado de un vaivén corporal ostentoso. Texto e indumentaria expresan, en su esquema más básico, la tradicional división de roles y la batalla de los géneros.

Es importante reparar en que los nombres genéricos de los personajes -He y She- apoyan el carácter social del gesto: aquí no interesan los individuos particulares sino el colectivo al que pertenecen, en este caso hombres y mujeres. En su método de trabajo, Judy Chicago proponía partir de la experiencia individual, para pasar a analizarla como un hecho social, descubriendo su origen estructural (Raven 1994). En el teatro de Brecht, también los personajes responden a arquetipos sociales, no tienen nombres propios sino genéricos: coronel, chico, madre, cocinero... De igual modo procedió August Sander al explorar el orden social a través de sus retratos.

Cock and cunt play se enmarca en dos estancias del hogar -la cocina y el dormitorio- lugares privilegiados para revelar la desigualdad, los conflictos emocionales y las relaciones de dominación. Estancias omnipresentes en la película Jeanne Dielman, 23 quai du Commerce, 1080 Bruxelles (1975) de Chantal Akerman. En largos planos filmados en la cocina asistiremos a las tareas domésticas que la protagonista realiza meticulosamente. En una ceremonización de las actitudes más corrientes, más vulgares y triviales, cada gesto está coreografiado y es realizado pausadamente. Chantal Akeman, devolviendo el discurso al cuerpo y con una puesta en escena estilizada, provoca que reconozcamos una situación real con asombro, nos descubre la neurosis del ama de casa.

En la pieza de Judy Chicago es en el dormitorio donde He mata a She; en el film de Akerman también es escenario de la violencia, donde la protagonista asesina a su cliente sexual. Como bien observa Giulia Colaizzi, la larga sucesión de cuadros que muestran la banalidad cotidiana, casi en tiempo real, produce un efecto aumentado sobre el desenlace, lo percibimos "brutal e inesperado, especialmente en el contexto de la previsibilidad y repetitividad de las acciones representadas hasta ese momento" (Colaizzi 1995, 35).

Además de que la domesticidad, la maternidad y la prostitución eran temas en la agenda feminista, la película de Akerman será aclamada por la crítica feminista como exponente del nuevo contracine feminista y por ofrecer una nueva forma de mirar que apelaba a una espectadora femenina: "es un retrato de la experiencia femenina, de duración, percepción, hechos, relaciones y silen- 
cios que se perciben como incuestionablemente verdaderos (...) la película de Akerman se dirige al espectador como mujer" (De Lauretis [1985] 1992, 261).

Estrenada en el mismo año en que se publica el célebre texto de Mulvey (1975), en el film se rechazan el uso del plano/contraplano, de los planos cortos, de la edición ágil; se afirma una radical producción de la duración y se eliminan todos los mecanismos cinematográficos del voyerismo sádico y la objetualización sexual: "La posición fija y baja de la cámara de Akerman y las largas tomas fueron bienvenidas como signos de una nueva gramática feminista que evitaba objetualizar a la mujer dentro del cine mientras que permitía, mediante la desobediencia radical a las convenciones de Hollywood, un espacio representacional para inscribir a la mujer como un sujeto, para crear una narrativa, sin embargo ambivalente, de la subjetividad femenina en su sujeción a lo doméstico" (Pollock 2013, 325).

El vídeo también será usado como una tecnología de género desde donde se performe una rebelión ante dicha sujeción. Coetáneo al film de Akerman es Semiotics of the kitchen (1975), donde Martha Rosler imprime al cuerpo un gesto excesivo, cargado de ira y frustración, para ejemplificar un uso violento, e insólito, de los utensilios de cocina. La violencia también amenaza con desencadenarse en las inquietantes escenificaciones fotográficas que Laurie Simmons realiza entre 1976 y 1978: en diferentes habitaciones de una casa de muñecas, principalmente en la cocina, ceremoniza el cuerpo cotidiano valiéndose de una muñeca. Y la violencia aflora de nuevo en los videos Tortilla a la española (1999) de Pilar Albarracín, o en Ceia (2001) de Sandra Ramo: en ambas obras, los movimientos firmes y bruscos con que las autoras manipulan objetos cotidianos, los ruidos secos, la frialdad de materiales como el acero, y, en la pieza de Albarracín, la violencia implícita al uso de las tijeras, descubren, de nuevo, la insoportable situación de opresión de las mujeres en el espacio doméstico.

\section{GESTUS FEMINISTAS Y POLITIZACIÓN DEL ESPACIO PÚBLICO}

Al igual que el espacio doméstico, el espacio público ha sido politizado en numerosas obras gestuales feministas. No estamos siguiendo aquí la tradicional división entre ambos espacios, recordemos que el feminismo se ha encargado de desarmar la dicotomía entre lo público y lo privado. De hecho, la 
extensión al espacio público de las tareas asignadas a las mujeres, especialmente de los trabajos de limpieza y cuidados, ha sido objeto de varias obras performativas.

En ese sentido fueron pioneras las performances de Mierle Laderman Ukeles, en las que funde su trabajo doméstico con su actividad artística: en Private performances of personal maintenance as Art (1970-73) convierte las tareas y rutinas del hogar en un acto artístico; y en Hartford wash: Washing, tracks, maintenance (outside) (1973), realiza el gesto de limpiar la institución museística, visibilizando un trabajo que pasa inadvertido y reivindicando su necesidad para el funcionamiento de la sociedad.

Pocos años después, el colectivo británico Berwick Street -del que formó parte la artista Mary Kelly- realiza el documental Nightcleaners (1975) en el marco de una campaña para sindicalizar a las mujeres que trabajaban de noche, en condiciones precarias, en la limpieza de oficinas. También en 1975 Mary Kelly, junto con KayHunt y Margaret Harrison, convertirán en instalación una investigación en torno a las condicioneslaborales de 150 obreras de una fábrica de Bermondsey -Woman \& work: A document on the division of labour in industry (1973-1975). Y en ese mismo año, el colectivo Hackney Flashers -integrado, entre otras mujeres, por Jo Spence- realiza una exposición del mismo nombre -Woman \& Work- sobre la división sexual del trabajo y la desigualdad laboral. Exposición a la que recientemente ha hecho homenaje la muestra Women in Work. Dona, art i treball en la globalització (2017), comisariada por MauMonleón en Valencia.

En esta genealogía, podemos inscribir obras performativas recientemente realizadas en España como Contrageografías humanas (campaña de sensibilización frente a los roles asignados a las mujeres migrantes en España) (2008) de Mau Monleón o Dependencia mútua (2009) de Eulàlia Valldosera.

Otras vías de politización han llevado aparejados gestos que revelan la sexuación del espacio público. En la serie fotográfica de VALIE EXPORT Body configurations (1972-76), la artista adopta forzadas posturas para hacer encajar su cuerpo con la arquitectura urbana y la geometría, revelando relaciones sociopolíticas de imposición y de adaptación. En la conocida serie Untitled film stills (1977-80), Cindy Sherman encarna a la protagonista de un film inexistente, pero muy familiar, en el que nos deja ver a través del gesto corporal que la calle es un espacio masculinizado, un lugar inseguro para las mujeres. En los "fotogramas" son una constante las poses con la cabeza ligeramente 
inclinada, la actitud retraída de la mujer, el cuerpo recogido, el gesto serio, la mirada precavida dirigida hacia el entorno.

Numerosas artistas han denunciado la inseguridad y violencia experimentadas en el espacio público, en un ágora hecho a la medida de los sujetos varones. Célebres trabajos performáticos de los años 70 de artistas como Ana Mendieta, Suzanne Lacy and Leslie Labowitz o Mónica Mayer, han tenido continuidad en trabajos desarrollados a partir de los años 90 por artistas como Pilar Albarracín (Sangre en la calle, 1992), Regina José Galindo (El dolor en un pañuelo, 1999), Alicia Framis (Secret Strike Lleida, 2005) o Teresa Margolles (Sonidos de la muerte, 2008).

Tomando distinta dirección, otras artistas emprendieron gestos a través de los que, simbólicamente, se hacen con el ágora o irrumpen en él contraviniendo las normas de comportamiento socialmente sancionadas. Del contexto sesentayochista son emblemáticas las performances de VALIE EXPORT (Cine para tocar y palpar, 1968), Adrian Piper (Catalysis Series, 1970-73), Eleanor Antin (The King, 1972) o Fina Miralles (Petjades, 1976).

De nuevo, encontramos una continuidad de dichos gestos en artistas de las últimas décadas. Pipilotti Rist, aplicando un giro lúdico y reinterpretando el género de la performance, en el video Ever is over all (1997) nos muestra a una muchacha que avanza alegremente por la acera portando una enorme flor. Inesperadamente, la utiliza como para romper las ventanillas de los coches aparcados; una mujer policía va acercándose a ella y al alcanzarla, en vez de recriminarla por su conducta, la saluda con complicidad. El gesto de la protagonista es de gran ligereza, de arrolladora alegría; y el uso de la proyección ralentizada acentúa la teatralización de los movimientos corporales de la joven.

Itziar Okaritz (Mear en espacios públicos o privados, desde 2002) y Janine Antoni (Conduit, 2009) se apropian del gesto masculino de mear de pié, con sus consiguientes implicaciones de dominio. Con ese gestus Okariz afirma su cuerpo en diferentes espacios; Antoni se hace con Nueva York, meando desde la cima del edificio Chrysler.

En Rousseau y Sophie (2007), Cristina Lucas convoca a un grupo de mujeres, adultas y niñas, para "atentar" contra el homenaje que se le rinde en una plaza pública de Madrida uno de los padres de la llustración. Se trata de una acción de carácter festivo: con el acompañamiento de una fanfarria, las participan- 
tes desfilan por delante de Rousseau, golpeando el busto e insultándolo a su paso. Este gesto de venganza histórica se recoge en un video, donde la imágenes se acompañan de la lectura en voice-over de fragmentos del libro $\mathrm{V}$ de Emilio, o De la Educación. Texto en el cual Rousseau legitima la subordinación de las mujeres y dicta el destino social de Sofía.

Sharon Hayes ocupa el ágora y se hace con el discurso en Everything else has failed! Don't you think it's time for love? (2007). En pleno centro de Manhattan, a la hora del almuerzo, armada de micrófono y amplificador, se dirige a un supuesto amante. Hayes va entretejiendo lo personal con lo político: las palabras propias de una correspondencia privada, se entremezclan con comentarios sobre la política y la guerra. Su dicción es ensayada, las frases son espaciadas, los silencios calculados; Hayes utiliza la lengua demostrándonos que, como había contemplado Brecht, también puede ser un material gestual.

\section{Referencias}

Barthes, Roland. (1955) 2002. “Las enfermedades de la indumentaria teatral”. En Ensayos críticos, traduccion de Carlos Pujol, 71-82. Barcelona: Seix Barral

- . (1970) 1986. "El tercer sentido". En Lo obvio y lo obtuso: Imágenes, gestos, voces, traducción de C. Fernández Medrano, 49-67. Barcelona: Paidós

— . (1973) 1986. “Diderot, Brecht, Eisenstein”. En Lo obvio y lo obtuso: Imágenes, gestos, voces, traducción de C. Fernández Medrano, 93-101. Barcelona: Paidós

Benjamin, Walter. (1931) 1999. "Qué es el teatro épico” (primera versión): Un estudio sobre Brecht". En Tentativas sobre Brecht: Iluminaciones III, prólogo y traducción de Jesús Aguirre, 15-29. Madrid: Taurus

- . (1934) 2001. "El autor como productor". En Arte después de la modernidad: Nuevos planteamientos en torno a la representación, Brian Wallis, ed.; traducción, Carolina del Olmo y César Rendueles, 297-309. Madrid: Akal

Brecht, Bertolt.(1947) 2004. Escritos sobre teatro. Selección Jorge Hacker; traducción de Nélida Mendilaharzu Machain Barcelona: Alba

Colaizzi, Giulia, ed. 1995. Feminismo y teoría fílmica. Traducción castellana de Manuel Talens. Valencia: Episteme

De Lauretis, Teresa. (1985) 1992. "Repensando el cine de mujeres: Teoría estética y feminista". Debate Feminista 5:251-277

- . 1989. Tecnhologies of gender: Essays on theory, film and fiction. London: Macmillan

Deleuze, Gilles. (1983) 1994. La imagen-movimiento: Estudios sobre cine 1. Traducción de Irene Agoff. Barcelona: Paidós

- . (1985) 1996. La imagen-movimiento: Estudios sobre cine 2. Traducción de Irene Agoff. Barcelona: Paidós

Mulvey, Laura. (1975) 1988. Placer visual y cine narrativo. Versión castellana de Santos Zunzunegui. Valencia: Eutopías 
Pollock, Griselda. 2013. After-affects/After-images: Trauma and aesthetic transformation in the virtual feminist museum. Manchester: Manchester University

Raven, Arlene. 1994. "Womanhouse". En The power of feminist art: The American movement of the 1970s: History and impact, Norma Broude \& Mary D. Garrard, eds., 48-65. New York: Harry N. Abrams

Sánchez Martínez, José Antonio. 2007. Prácticas de lo real en la escena contemporánea. Madrid: Visor

(Artículo recibido 03-05-18; aceptado 21-05-18) 